Demczuk, R., Korelo, J. C., Mantovani, D., \& Prado, P. H. M. (2020). Product (Un)availability and Shopping Mind-set in Sequential Purchases. Consumer Behavior Review, 4(3), 189-198.

ISSN: 2526-7884

Editor: Prof. Dr. Marconi Freitas da Costa Journal's e-mail: cbr@ufpe.br
Evaluation: Double blind review

Received: April 30, 2020

Accepted: August 20, 2020

\title{
PRODUCT (UN)AVAILABILITY AND SHOPPING MIND-SET IN SEQUENTIAL PURCHASES
}

(In)disponibilidade do produto e Shopping Mind-Set nas Compras Sequenciais

\author{
Rafael Demczuk ${ }^{1}$ \\ ORCID: http://orcid.org/0000-0001-8567-5098 \\ E-mail: rafaeldemczuk@gmail.com \\ José Carlos Koreto ${ }^{1}$ \\ ORCID: http://orcid.org/0000-0002-2918-5809 \\ E-mail: korelo@ufpr.br \\ Danielle Mantovani ${ }^{1}$ \\ ORCID: http://orcid.org/0000-0001-7456-304X \\ E-mail: danielle@ufpr.br \\ Paulo Henrique Muller Prado ${ }^{1}$ \\ ORCID: http://orcid.org/0000-0002-7351-6089 \\ E-mail: pprado@ufpr.br
}

${ }^{1}$ Programa de Pós-Graduação em Administração, Universidade Federal do Paraná, Curitiba, Brazil

\begin{abstract}
Drawing on consumer choice process and implementation theory, this study investigates how product (un)availability influences consumers shopping mind-set and the likelihood of purchasing a second unrelated product. Two studies were applied using a single factor experimental design with two conditions (product: availability vs. unavailability) on consumer' purchase
\end{abstract}

Resumo
Fundamentado no processo de escolha e na
teoria da implementação, este estudo
investiga como a (in)disponibilidade do
produto influencia o mind-set dos
consumidores e a probabilidade de
comprarem um segundo produto não
relacionado. Dois estudos são apresentados
com design experimental de fator único com
duas condições (produto: disponibilidade vs.

Resumo

Fundamentado no processo de escolha e na teoria da implementação, este estudo investiga como a (in)disponibilidade do produto influencia o mind-set dos consumidores e a probabilidade de comprarem um segundo produto não duas condições (produto: disponibilidade vs. 
intention. The results demonstrate when the product is out-of-stock (i.e., unavailable) the propensity to purchase a second unrelated product is higher, compared to when the first product is available for purchase. This study contributes to the literature of the constructive choice process showing that product unavailability does not reduce the shopping implementation. Once a choice is made but not performed, consumers will try to implement their purchase intention in subsequent options. From a managerial perspective, this study provides possibilities for managers to redirect the shopping implementation to alternative options.

Keywords: Out-of-stock, Product availability, Sequential choice, Shopping mind-set. indisponibilidade) na intenção de compra do consumidor. Os resultados demonstram que, quando o produto está indisponível, haverá maior propensão de compra de um segundo produto não relacionado em comparação com a disponibilidade do primeiro produto. Este estudo contribui para a literatura do processo de escolha construtiva mostrando que a indisponibilidade do produto não reduz a intenção de implementação dos consumidores. Uma vez que uma escolha é feita, mas não executada, os consumidores tentarão implementar sua intenção de compra nas opções subsequentes. $\mathrm{Na}$ perspectiva gerencial, este estudo oferece possibilidades para que os gerentes redirecionem a implementação de compras dos consumidores para opções alternativas.

Palavras-chave: Indisponibilidade de estoque, Disponibilidade do produto, Escolha sequencial, Shopping mind-set.

\section{INTRODUCTION}

The phenomenon of product unavailability is a common situation in everyday shopping activities. In fact, even big companies face out-of-stock problems. In 2018 Walmart failed to keep some essential items in their stock over the holidays, resulting in negative consequences for the business and their customers (Business Insider, 2018). However, consumers do not always stop shopping because they had not found a product they had previously planned to buy.

For instance, imagine the following situation: After choosing a pair of shoes in a shop showcase, a woman enters the store and asks to try the desired shoes, but the salesperson informs that the requested number is no longer available. She gets a little upset, but right after this incident the salesperson informs that there are other products on sale in the store, offering her a pretty purse, which she likes very much. Would she buy another unrelated product (the purse), once she did not implement her first shopping decision (the desired shoes)? And what if she had found the right pair of shoes, would she pay more or less attention to other products?

We build on the literature from decision-making process (Bettman, Luce, \& Payne, 1998), which shows that the constructive choice process is constituted by two steps, deliberation and implementation mind-sets. Since consumers have pointed out the pros and cons of the options (deliberation mind-set), they will decide which option best meets their goals, leading to the purchase process (implementation mind-set; Gollwitzer, 1990; Dhar, Huber, \& Khan, 2007). Past research shows that when consumers decide to make an initial purchase (choose to buy a driver item), they will enter in an implementation process, making them more likely to buy a second product (to purchase a target item; Dhar, Huber, \& Khan, 2007).

Furthermore, when consumers establish a preference among a set of options, even when they are asked to define their preferences in unrelated domains to the purchase scenario, consumers will shift the deliberation to an implementation mind-set (Xu \& Wyer, 2007; Xu \& Wyer, 2008). This effect is mainly driven by mind-sets that once activated will determine subsequent behaviors, increasing consumers' likelihood to make an acquisition in a subsequent purchase situation. Therefore, we suggest that the implementation mind-set should be applied to subsequent purchases even when the driver product is unavailable. 
Although extensive research has analyzed out-of-stock and its consequences to retail stores (Ma, Chen, \& Zheng, 2018; Huang \& Zang, 2016; Diels, Wiebach, \& Hildebrandt, 2013), at time there is no evidence that shows how product unavailability impacts shopping mind-set. We propose that product unavailability may influence the willingness to buy a second target product in a choice set. More specifically, we argue that after deliberating about buying a product, the probability of purchasing a second item is higher if the first option is not available when compared to the situation where the first option is available. This effect arises because of the shopping mind-set. Once consumers do not implement their shopping purpose in a driver item, they will direct this shopping goal to the next buying opportunity.

This research contributes to the literature on constructive choice process at the stage of implementation intention, showing that consumers are more likely to turn their attention to a second unrelated product when the first option is not available for purchase. Past research shows that when consumers buy a first driver product, the probability to purchase a second unrelated target product increases because of the shopping momentum effect (Dhar, Huber, \& Khan 2007). This study contributes to this previous finding showing that shopping momentum mind-set seems to be even stronger when the goal to purchase the first option is not accomplished. This research also contributes to the studies on product (un)availability, highlighting the consequences for subsequent purchase behavior under this situation. Besides the great amount of studies showing the negative impacts of out-of-stock, such as sales and profit reduction, negative product evaluation, and consumers' dissatisfaction (Fitzsimons, 2000; Puligadda et al., 2012; Hsuan-Hsuan, Chien-Chih, \&Wan-Ting 2017; Ma, Chen, \& Zheng, 2018), this study indicates that consumers may pay more attention to other products when the first choice is unavailable.

In the following sections the literature on implementation mind-set and its relationship with product (un)availability is reviewed, suggesting the main theoretical proposition of this research. Two studies are conducted offering support for our prediction. We conclude with a general discussion of theoretical and managerial implications and suggestions for future research.

\section{THEORETICAL BACKGROUND}

\section{Implementation Intention and Product (un)availability}

Consumer decision-making activities are guided by a series of cognitive processes, which will be activated during the planning and through the execution of relevant actions to successfully achieve a desired end state (Henderson, Liver, \& Gollwitzer, 2008; Fujita, Gollwitzer, \& Oettingen, 2007). These processes are characterized as consumers' mind-sets.

Extant research has postulated that mind-set is composed by two phases, deliberation and implementation (Gollwitzer \& Bayer, 1999; Achtziger \& Gollwitzer, 2008; Wyer, 2018). In a deliberative mind-set, consumers will weigh the pros and cons of each alternative, determining which goal will better achieve the desired end, whereas in the implementation mind-set they will structure the steps aiming to steer behaviors and actions to reach a consumption goal (Fujita, Gollwitzer, \& Oettingen 2007; Xu \& Wyer, 2007).

As a consequence of the described process, when consumers are in a deliberation mind-set they will collect the needed information for decision-making, unlike the implementation, in which the execution of the elaborated plan occurs. More important to this research, when mind-set is evoked it will persist, guiding consumers' behavior through the acquisitions (Dhar, Huber, \& Khan, 2007; Ramanathan \& Dhar, 2010; Stilley, Inman, \& Wakefield, 2010). Likewise, when consumers decide which product they want to buy, they will automatically categorize all the options under the choiceset, increasing their propensity to continue making purchases through implementation mind-set maintenance (Xu \& Wyer, 2007; Xu \& Wyer, 2008).

Following this perspective, Dhar, Huber, and Khan (2007) proposed the Shopping Momentum Effect, a process that occurs when the purchase of a first product increases the likelihood of purchasing a subsequent item. The authors show that when consumers buy the first driver product, the probability to implement subsequent purchases in an unrelated domain increases compared to the 
conditions where consumers decide not to buy the first driver option. Despite the effort of scholars exploring subsequent purchases when the first option is available, there is little evidence about the consequences for subsequent purchase intentions when consumers are faced with the first driver item unavailability.

Past research on mind-set theory has analyzed how consumers evaluate and make subsequent decisions (Xu \& Wyer, 2008; Kim \& Meyers-Levy, 2008; Raeva, van Dijk, \& Zeelenberg, 2011; Cheng \& Leung, 2012) and research on product (un)availability has investigated the effects of out-of-stock on consumers' attitudes (Kristofferson et al., 2017; Ma, Chen, \& Zheng, 2018), and the relation between out-of-stock and consumers reactions in a promotion-based context (Diels, Wiebach, \& Hildebrandt, 2013). The relation between out-of-stock and the shift on consumers preference among the in-stock options has also been investigated (Boland, Brucks, \& Nielsen, 2012; Huang \& Zhang, 2016). For instance, Huang and Zhang (2016) found that consumers can draw social inferences from out-of-stock about the desirability of product features. Consequently, in-stock options that share features with the out-of-stock option enjoy a choice advantage. This evidence shows that when consumers are faced with product (un)availability, the perceptions about other products might be highlighted. Therefore, it is possible that product (un)availability might differently impact consumers' implementation mindsets and the probability to make sequential purchases.

Thus, the phenomenon of sequential purchases regarding implementation mind-set maintenance was studied only under availability condition. Here, we propose that when the first driver product is not available for purchase, the shopping mind-set will remain activated, prompting the probability of consumers to buy a second target product. In other words, when consumers complete the deliberation mind-set stage and enter in an implementation mind-set, this mental process will be remaining activated and will drive consumers' subsequent decisions even though when the first driver product is unavailable.

We run two experiments to test these predictions. First, we provide evidence that the first driver item unavailability maintains consumers in implementation mind-set, increasing the probability to buy a second target item, compared to those that were able to make to first purchase. In the second experiment, we replicate this effect with a behavioral dependent variable.

\section{EXPERIMENT 1}

The goal of this study is to establish initial support to our main prediction that product unavailability, in a set of items, could lead consumers to increase their likelihood to buy a second target product. More specifically, consumers will be more likely to buy a target product when they are exposed to a set of items and when the driver option is unavailable (vs. when driver product is available).

\section{Method}

Participants and Design. This study employed a single-factor design with two conditions (first driver item: available vs. unavailable). The driver item is the first product that consumers manifest the intention to buy. The sample was composed only by participants who were willing to purchase the first driver item. Those who decide to do not buy the driver item were removed from our sample. Our final data was composed by one hundred forty-one participants ( $56.6 \%$ female; $\left.M_{\text {age }}=23.39\right)$ that were recruited in an online panel, which was composed mainly by undergraduate students.

Procedure. Respondents were introduced to a scenario that asked to imagine an online purchase decision, receiving a virtual credit of $\$ 15.00$. More specifically, individuals read the following information:

"You will participate in a survey involving the provision of some items for a purchase decision. Please, when the list of products appears on the screen imagine that you are visiting an online shopping of your preference. Try to visualize as vivid as possible that the presented products are sold by the selected store. Therefore, we are providing you an initial credit of $\$ 15.00$ for participating in this survey. This credit can be used for this study, or you can keep the money for 
you. At the end of the study you will participate in a lottery. If you are awarded, you will receive the credit and/or the selected purchased items."

Participants were randomly assigned to one of the two conditions. Respondents were exposed to five products randomly selected from a set of 8 items (mug, keychain, set of sticky notes, set of pens, stapler, desk paper organizer, plastic squeeze, and scissors, which were selected based on its attractiveness, necessity, and likelihood of purchase with an unrelated sample), each one costing $\$ 3.00$. The five products were randomized per individual. After visualizing the pictures of the products, participants were asked about their intention to purchase a driver item: "We would like to know if you are interested in buying any of these items. Remember that you can use your credit (\$15.00) for this purchase."

When participants decided to make a purchase, they were then allocated to one of the two driver item (un)availability conditions. In the first driver item unavailability condition, respondents received the following message: "Sorry for the inconvenience, but the selected item is out-of-stock. You still have your $\$ 15.00$ of credit." In the first driver item availability condition, respondents read a message about the successful purchase process: "Purchase completed successfully! Thank you for choosing this item; you have a credit of \$12.00." Participants were then exposed to the four remaining products. Afterward, they were asked if they would like to buy another item. The virtual purchase of the second target item was the dependent variable. All participants were able to keep buying items until they had remaining credits. After finishing the shopping process, participants answered demographic questions.

\section{Results}

A logistic regression was run to test the impact of the driver product (un)availability on intention to purchase the second target product. The predictor was coded as first driver item unavailability $=1$ and first driver item availability $=0$. The dependent variable was coded as second target item purchased $=1$ and second target item not-purchased $=0$. The results show a significant main effect of the product (un)availability condition on intention to purchase the second target product (unavailability vs. availability; $\beta=1.100$; $\operatorname{WaldX}^{2}(1,141)=5.517 ; p=.019$; Odds Ratio $=$ 3.005; see figure 1).

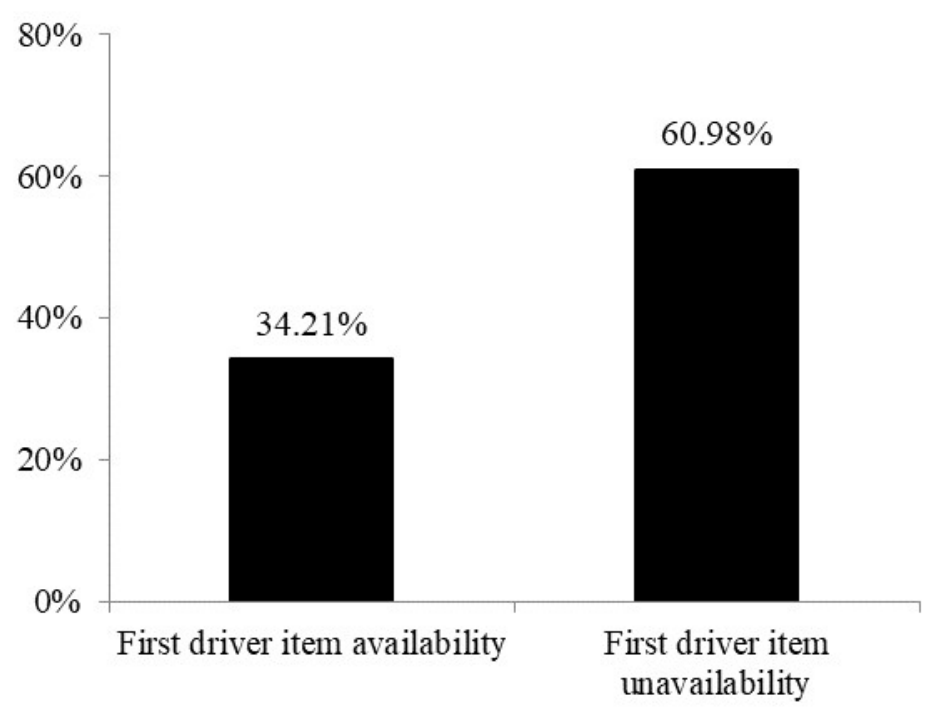

Figure 1 - Second Target Item Purchase (Study 1)

Consumers showed a higher purchase intention when assigned to the first driver item unavailability $(60.98 \%)$, compared to the first driver item availability condition $\left(34.21 \% ; X^{2}=10.383\right.$, 
$p=.001)$. These results confirm the main prediction of this study. There were no effects of the first driver item preference on subsequent purchases $(p>.50)$.

\section{Discussion}

These findings show initial evidence that consumers will sustain a shopping mind-set when the first driver product is not available. However, when consumers are free to purchase the first driver item, they complete the shopping implementation goal. Therefore, the willingness to buy a second target item will reduce when compared to the first driver item unavailability condition.

Although this result supports the main prediction of this research, a few concerns must be highlighted. First, Experiment 1 was based on a hypothetical scenario, which may be distant from reality and somehow influence the results we have found. Second, Experiment 1 relied on a subjective dependent variable. Although they participated in a lottery to be awarded with the credit and the products they bought, it is an open question whether these findings would be replicated if the participants are faced with an actual financial decision. We address these issues in Experiment 2.

\section{EXPERIMENT 2}

The primary purpose of experiment 2 is to replicate the findings obtained in the first study while addressing the two concerns emphasized previously. To be precise, this experiment uses (a) a simulated shopping process in a more realistic situation, in which participants were exposed to a real set of products, and (b) a slightly more consequential dependent variable.

\section{Method}

Participants and Design. One hundred and nine undergraduate students (52.3\% female; $M_{\text {age }}=$ 21.24) participated in a single factorial, between-subjects design resulting in two conditions (first driver item: availability vs. unavailability).

Procedure. Respondents were invited to participate in a series of unrelated studies, receiving $\$ 5.00$ as a reward. In a room organized for our main study, six products were randomly displayed in a table (cereal bar, post-it, text marker, chewing gum, pencil, and a pair of socks). These products were selected based on a pre-test with an unrelated sample, which evaluated the attractiveness, necessity, and likelihood of purchasing each item. These products were also selected because they are frequently consumed by undergraduate students.

Participants were then informed that these products had been left over from a previous study and each of them was being offered at the cost of $\$ 1.00$. Next, the experimenter asked the participants if they would like to buy any of the presented products (Would you like to buy any of these items for $\$ 1.00$ ?). On the first driver unavailability condition, after the product choice, the experimenter checked its availability in a separate 'inventory shelf.' Then, respondents were notified that the first selected product was not available in stock. Afterward, participants were questioned if they would like to buy any other item for $\$ 1.00$ (Would you like to buy another item for $\$ 1.00$ ?). The purchase of the second target product was our dependent variable. If they decided to buy any product, the experimenter returned to the inventory shelf, verified its availability and delivered the product. The experimenter performed the same procedure until the respondent decided not to buy any additional product. On the availability condition, the same process was adopted, with the exception that participants were able to buy the first driver product without restrictions. Finally, participants provided their demographic data (gender and age).

\section{Results}

Similarly to Experiment 1, a logistic regression tested the difference on the purchase of a second target product option across product (un)availability conditions. The independent variable was coded as first driver item unavailability $=1$ and first driver item availability $=0$. The dependent variable was coded as second target item purchased $=1$ and second target item not-purchased $=0$. The analysis revealed a significant main effect of the product (un)availability condition on intention to 
purchase the second target product (unavailability vs. availability; $\beta=1.166, X^{2}(1,109)=8.358, p<$ .01 , Odds Ratio $=3.209$; see Figure 2).

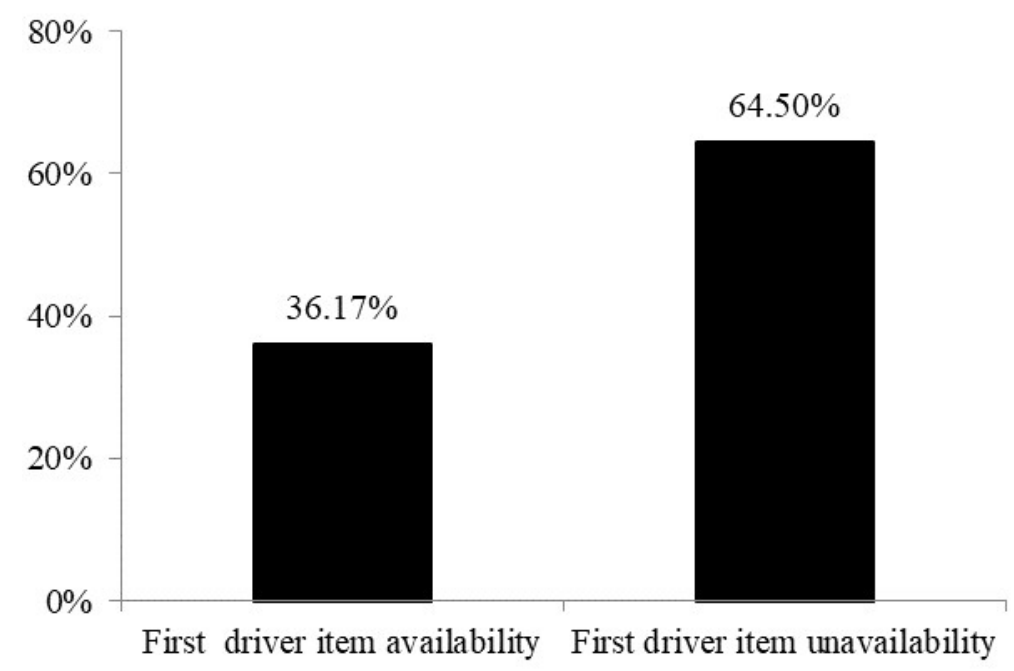

Figure 2 - Second Target Item Purchase (Study 2)

When participants were exposed to the first driver item unavailability, the rate of the second target item purchase was higher (64.5\%) compared to the first driver item availability condition (36.17\%). Again, we did not find significant effects of the first driver item preference on subsequent purchases $(p>.50)$. These results corroborate those found in Experiment 1 and also given additional support to our main prediction of this research.

\section{Discussion}

The results of Experiment 2 successfully replicated those obtained in Experiment 1, addressing a more consequential dependent variable. The results demonstrate that the purchase rate of the second target product was affected by the product (un)availability condition. The choice process is sufficient to trigger an implementation mind-set, which will remain activated for subsequent purchase opportunities even when the first selected option is unavailable. As a result, under the first item unavailability condition, the likelihood to purchase the second target product is higher, compared to when the first driver item is available.

\section{GENERAL DISCUSSION}

This research examines how a driver item (un)availability influences individuals' propensity to purchase a second target product, an effect that is guided by the maintenance of the implementation mind-set. Two experiments demonstrate that the shopping implementation mind-set will guide consumers' actions. More specifically, when individuals are confronted to the first driver item unavailability, the willingness to buy a second target product will increase when compared to the first driver availability situation (Experiment 1). This effect is confirmed by applying a more reliable dependent variable (Experiment 2). Participants actually bought the second target item more frequently when the first driver item was not available for purchase.

These results contribute to the literature of consumer decision making and choice process (Bettman, Luce, \& Payne, 1998; Ehrich \& Irwin, 2005; Leisti \& Häkkinen, 2017) in some particular points. This study adds to the shopping continuity effect (Dhar, Huber, \& Khan, 2007; Ramanathan \& Dhar, 2010; Stilley, Inman, \& Wakefield, 2010) showing that product (un)availability is an important driver of the shopping mind-set. Consumers will keep the shopping implementation mind-set when they do not find the first chosen product. The goal to make a purchase will remain salient until a 
purchase is made. When consumers are able to implement their choice, the shopping goal will be reduced and will have a weaker influence on subsequent purchases.

Our empirical findings also provide suggestions to retailers about how to make consumers maintain the shopping implementation mind-set under the out-of-stock situation. For instance, the sales team should be trained to offer to customers a second target option when the first driver product is out-of-stock. Therefore, if a consumer does not find the right pair of shoes that first called its attention, maybe a new purse or a shirt on sale could also look interesting. For self-service stores, where sellers are not around to influence customers' preferences and choices, managers could have more products on sale or use other promotional strategies to redirect attention to second target products when the first driver item is out-of-stock. For instance, if a favorite brand of shampoo is unavailable, a body moisturizer on sale may look interesting as a subsequent purchase option.

\section{Limitations and Future Research Directions}

Besides its contributions, some limitations of this study must be highlighted. One potential limitation of Experiment 1 is the stimuli under an artificial environment scenario, which is far from the natural atmosphere that consumers often find in a real purchase situation. In Experiment 2, although participants were exposed to real products, the shopping environment is not identical to a real retail store.

The prices of the items used in both studies were identical in order to control the effect of price differences on consumers' preferences. However, this may also raise a potential limitation, since these products may have different prices in a real retail environment and participants compare them with the regular prices they find. Another limitation is the difference in the amount of money between the (un)availability conditions. Those in the first driver product availability condition were able to make the first purchase, which reduced their available balance for subsequent purchases. Although they still had enough money to make subsequent purchases and the products were of low involvement, there is a chance that this could have influenced subsequent decisions.

One particular alternative explanation to consider is that there may be a level of obligation to buy felt by the respondents during the procedures. Once consumer have expressed an interest to buy and engages with the sales person, there is an interaction, which may result in a possible expectation that this customer should buy at least something. However, if the product of preference is not available, the consumer has the license to finish the purchase process. If they demonstrate a higher willingness to buy subsequent products, the implementation intention might still be active.

Moreover, our results suggest that consumers may follow a choice hierarchy given the unavailability of the first driver item, but the relationship between the product (un)availability and this phenomenon was not investigated in this study, which presents an opportunity for future researches to clarify this phenomenon.

Additionally, both experiments were based on low-involvement products, but this effect is not clear when consumers face this phenomenon under high-involvement products choice. For instance, you may go to a store interested in a new cell phone, which is a high-involvement product. But if your choice is unavailable, what is the probability that you may find another unrelated product interesting? Consumers also have their preferred brand when deciding which product to buy and the brands make large investments to maintain their brand awareness in the consumer's mind. Given this explanation a question remains, will consumers change their assortment planning when considering products that have a high or a low brands equity? These questions present avenues for future researches.

Also, our research does not investigate the possible reasons for consumers to keep the implementation mind-set under product unavailability. One possible explanation is that consumers attempt to complete a transaction given that they already invested effort and time into considering a purchase. It is important to identify the reasons to keep the shopping implementation because they may highlight possibilities to resolve the out-of-stock problems faced by managers every day at the retail store. Finally, when exposed to an assortment of products, will consumers present the same buying propensity when presented to first item unavailability if we highlight a hedonic versus a 
utilitarian motivation? And what if we offer a related product (i.e. a pair of shoes as first option and a belt as second option) or an unrelated product (i.e. a shirt as first option and a perfume as a second option), will the purchasing pattern found remain? Future research could further address these issues.

\section{References}

Achtziger, A., \& P. Gollwitzer. (2008). Motivation and Volition in the Course of Action. In J. Heckhausen \& H. Heckhausen (Eds.), Motivation and Action (pp. 272-295). Cambridge: Cambridge University Press.

Bettman, J. R., Luce, M. F., \& Payne, J. W. (1998). Constructive consumer choice processes. Journal of Consumer Research, 25(3), 187-217.

Boland, W. A., Brucks, M., \& Nielsen, J. H. (2012). The Attribute Carryover Effect: What the "Runner-Up" Option Tells Us about Consumer Choice Processes. Journal of Consumer Research, 38(5), 872885.

Business Insider. (2018). Walmart just had its worst day in 30 years - here's why. Accessed: August 1, 2018. <https://www.businessinsider.com/walmart-inventory-problems-slow-online-salesgrowth-2018-2>.

Cheng, C., \& Leung, A. K. (2012). Revisiting the Multicultural Experience-Creativity Link: The Effects of Perceived Cultural Distance and Comparison Mind-Set. Social Psychological and Personality Science, 4(4), 475-482.

Dhar, R., Huber, J., \& Khan, U. (2007). The shopping momentum effect. Journal of Marketing Research, $44(3), 370-378$.

Diels, J. L., Wiebach, N., \& Hildebrandt, L. (2013). The impact of promotions on consumer choices and preferences in out-of-stock situations. Journal of Retailing and Consumer Services, 20(6), 587598.

Ehrich, K. R., \& Irwin, J. R. (2005). Willful Ignorance in the Request for Product Attribute Information. Journal of Marketing Research, 42(3), 266-277.

Fitzsimons. G. J. (2000). Consumer Response to Stockouts. Journal of Consumer Research, 27(2), 249266.

Fujita, K., Gollwitzer, P. M., \& Oettingen, G. (2007). Mind-sets and pre-conscious open-mindedness to incidental information. Journal of Experimental Social Psychology, 43(1), 48-61.

Gollwitzer, P. M. (1990). Action phases and mind-sets. In: Higgins, E. T.; Sorrentino, R. M. Handbook of motivation and cognition. Foundations of social behavior, 2, pp. 53-92. New York: Guilford Press, 1990.

Gollwitzer, P. M., \& Bayer, U. (1999). Deliberative versus implemental mind-sets in the control of action. In: Chaiken, S. (Ed.). Dual-process theories in social psychology, pp. 403-422. New York [u.a.]: Guilford Press.

Henderson, M. D., Liver, Y., \& Gollwitzer, P. M. (2008). The Effects of an Implemental Mind-Set on Attitude Strength. Journal of Personality and Social Psychology, 94(3), 396-411.

Hsuan-Hsuan, K., Chien-Chih, K., \& Wan-Ting, H. (2017). Message-related effects on consumer switching when the preferred product is out of stock. European Journal of Marketing, 51(5/6), 1091-1109.

Huang, Y., \& Zhang, C. Y. (2016). The out-of-stock (Oos) effect on choice shares of available options. Journal of Retailing, 92(1), 13-24.

Kim, K., \& Meyers-Levy, J. (2007). Context Effects in Diverse-Category Brand Environments: The Influence of Target Product Positioning and Consumers' Processing Mind-Set. Journal of Consumer Research, 34 (6), 882-896.

Kristofferson, K., McFerran, B., Morales, A. C., \& Dahl, D. W. (2017). The Dark Side of Scarcity Promotions: How Exposure to Limited-Quantity Promotions Can Induce Aggression. Journal of Consumer Research, 43(5), 683-706. 
Leisti, T., \& Häkkinen, J. (2017). Learning to Decide with and without Reasoning: How Task Experience Affects Attribute Weighting and Preference Stability. Behavioral Decision Making, 31, 367-379.

Ma, K., Chen, T., \& Zheng, C. (2018). Influence of thinking style and attribution on consumer response to online stockouts. Journal of Retailing and Consumer Services, 43, 218-225.

Puligadda, S., Ross, W. T., Chen, J., \& Howlettc, E. (2012). When loyalties clash purchase behavior when a preferred brand is stocked out: The tradeoff between brand and store loyalty. Journal of Retailing and Consumer Services, 19(6), 570-577.

Raeva, D., van Dijk, E., \& Zeelenberg, M. (2011). How comparing decision outcomes affects subsequent decisions: The carry-over of a comparative mind-set. Judgment and Decision Making, 6(4), 343350.

Ramanathan, S., \& Dhar, S. K. (2010). The Effect of Sales Promotions on the Size and Composition of the Shopping Basket: Regulatory Compatibility from Framing and Temporal Restrictions. Journal of Marketing Research, 47(3), 542-552.

Stilley, K., M., Inman, J. J., \& Wakefield, K. L. (2010). Spending on the Fly: Mental Budgets, Promotions, and Spending Behavior. Journal of Marketing, 74(3), 34-47.

$\mathrm{Xu}$, A. J., \& Wyer, R. S. Jr. (2007). The effect of mind-sets on consumer decision strategies. Journal of Consumer Research, 34, 556-566.

Xu, A. J., \& Wyer, R. S. Jr. (2008). The comparative mind-set: from animal comparisons to increased purchase intentions. Psychological Science, 19(9), 859-864.

Wyer, R. S. Jr. (2018). The role of mindsets, productions, and perceptual symbols in goal-directed information processing. Consumer Psychology Review, 1, 90-109. 